ECCOMAS

Proceedia
COMPDYN 2021

$8^{\text {th }}$ ECCOMAS Thematic Conference on Computational Methods in Structural Dynamics and Earthquake Engineering M. Papadrakakis, M. Fragiadakis (eds.)

\title{
SEISMIC RESPONSE OF SEVEN EXISTING REINFORCED CONCRETE CHIMNEYS EQUIPPED WITH TUNED MASS DAMPERS UNDER FIVE STRONG SEISMIC EVENTS
}

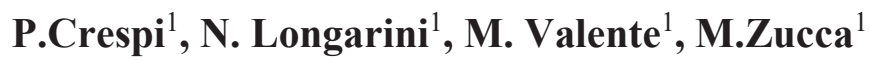 \\ ${ }^{1}$ Department of Architecture, Built Environment and Construction Engineering \\ Politecnico di Milano, Milano, Italy
}

\{pietro.crespi, nicola.longarini, marco.valente, marco.zucca\}@polimi.it

\begin{abstract}
The seismic response of seven existing reinforced concrete chimneys equipped with optimized Tuned Mass Dampers (TMDs) are investigated under five acceleration time histories recorded during different important European seismic events. For each chimney, the features of the TMDs are detected by nonlinear dynamic analyses, starting from the investigation about the optimum mass ratio (between the optimum mass of the TMD and the mass of the chimney without the TMD involved in the most representative vibrational modes). By the application of sinusoidal forces, the contribute of the TMDs are evaluated by the estimation of the equivalent damping ratio.
\end{abstract}

Keywords: Tuned Mass Damper, RC chimney, Seismic Response, Non-linear analysis.

ISSN:2623-3347 (c) 2021 The Authors. Published by Eccomas Proceedia.

Peer-review under responsibility of the organizing committee of COMPDYN 2021.

doi: $10.7712 / 120121.8782 .18732$ 


\section{INTRODUCTION}

All over the world many industrial plants are characterized by the presence of chimneys. Starting from the ' 50 of the 20th century, in the new manufacturing and chemical plants reinforced concrete $(\mathrm{RC})$ chimneys were built instead of the masonry traditional ones, due to plants requirements derived from the industrial developments and environmental reasons. From the middle of the 20th century, thanks to the new concrete techniques in use, it was possible to satisfy the new industrial processes requirements by reducing the environmental impacts with a significant height increasing (up to about $400 \mathrm{~m}$ ), thus defining a wide range of possible heights from $100 \mathrm{~m}$ to $400 \mathrm{~m}$. It is remarkable many RC chimneys were designed without specific earthquake-resistant provisions, considering only the wind as horizontal force [1] even if in some European countries, e.g. in Italy, many chimneys were built in areas only nowadays considered as seismic regions [2]. It represents an evident structural negligence for the seismic performance of many existing RC chimneys in terms of resistance and ductility and for economic aspects. Under seismic loads, the chimneys are characterized by an inelastic response, different from the elastic behavior. The domain of higher modes vibration and large natural period vibration consistently drives to a complex global dynamic response during earthquake events, reporting extremely increase of structural stress states, possible brittle collapse [3-10].

A recent study [11] has pointed out 6 major chimney failures causes, from 739 study cases, statistically summarized. The damage of these RC chimneys was mainly caused by seismic and wind action, temperature stress and construction defect [9].

Several researches have made relevant considerations in the earthquake engineering field $[12,13]$ which revealed a sort of crack pattern of these slender constructions. In particular, they identified a failure-prone region at $1 / 3$ to $2 / 3$ also 0.8 of the height of a standard designed chimney, which concentrates inelastic deformations. It may occur when remarkable inertial force takes place in hazard earthquake, observing fractures in the horizontal, vertical, and inclined directions depicted after the strong motion. A predominance of cracks with $20-30 \mathrm{~mm}$ widths according to [11] was noticeable in many seismic events. It was observed the specific wind design cannot allow an adequate seismic response [12] in particular in terms of concrete stiffness with respect the concrete strength [14]. The increase of the height over $130 \mathrm{~m} \mathrm{ex}-$ poses chimneys to large displacements wreaking cracks which demand extensive rehabilitation. Moreover, the radius-thickness ratio feature has also relevant influence in the dynamic response that decreases the displacement with the growth of the radius-thickness. It can be observed in chimney tapered from bottom to top lesser displacement values than chimneys which are tapered from the bottom then becomes uniform at one-third height. Shell stress as well decreases with the increase of radius thickness ratio in a fully tapered chimney in respect of partially tapered chimney. Chimneys with heights ranging from $325 \mathrm{~m}$ to $350 \mathrm{~m}$ are vulnerable against seismic forces especially tin case of elliptical cross-section. However circular chimneys have higher displacement than the elliptical section ones with higher accelerations under the seismic events. For improving the seismic response an adequate representation of the chimneys and the earthquakes is mandatory as it is explained in $[9,10]$. In these studies, the efficiency of passive tuned mass dampers is also proposed as a valid cost-benefits solution[15]. In several cases, the use of a single TMD represents a valid solution in terms of structural and economic convenience. The contribute of the single TMD can be described by shifting period coupled to the damping increase characterized the new system represented by the chimney with the TMD are easily detected. 


\section{STRUCTURE OF THE PAPER}

In Section 3, starting from the features of the chimneys (3.1) and the ones of the seismic actions (3.2), for each chimney the parameters of the Tuned Mass Dampers (TMDs) are detected (3.3). In the Section 4 the contribute of the TMDs in terms of equivalent damping is evaluated whereas the energetic contributions are shown in Section 5 (where a comparison between the cases chimneys without TMDs and chimneys with TMDs is shown as well). Finally, Section 6 contains the remarks about the results characterized Section 4 and Section 5,

\section{IDENTIFICATION OF THE TUNED MASS DAMPERS FEATURES}

\subsection{Chimneys}

The seven RC chimneys here investigated were built from the " 60 to the first half of the ' 80 years. They are classified considering four main geometrical features: the height $(\mathrm{H})$, the geometrical slenderness $\lambda=H / D_{\text {base }}$, the taper ratio $t_{d}=D_{\text {top }} / D_{\text {base }}$ and the mass distributed along the height $\left(\mathrm{q}_{\mathrm{h}}\right)$, depending on the chimney materials and the structural configuration and where $D_{\text {top }}$ represents the external diameter at the top of the structure while $\mathrm{D}_{\text {base }}$ indicates the external diameter at the base of the structure. In Table 1 the main information about the chimneys are shown.

\begin{tabular}{cccccccc} 
Chimney & $\begin{array}{c}\mathrm{D}_{\text {base }} \\
{[\mathrm{m}]}\end{array}$ & $\begin{array}{c}\mathrm{D}_{\text {top }} \\
{[\mathrm{m}]}\end{array}$ & $\begin{array}{c}\mathrm{H} \\
{[\mathrm{m}]}\end{array}$ & $\mathrm{t}_{\mathrm{d}}$ & $\lambda$ & $\begin{array}{c}\mathrm{t}_{\mathrm{h}} \\
{[\mathrm{cm}]}\end{array}$ & $\begin{array}{c}\mathrm{q}_{\mathrm{h}} \\
{[\mathrm{kN} / \mathrm{m}]}\end{array}$ \\
\hline CH_1 & 4.8 & 2.5 & 60 & 0.52 & 12.50 & 30 & 76.50 \\
CH_2 & 16.1 & 13.6 & 100 & 0.85 & 6.21 & $40-30$ & 100.00 \\
CH_3 & 10.3 & 6.6 & 115 & 0.64 & 11.17 & $45-20$ & 71.00 \\
CH_4 & 15.0 & 14.8 & 120 & 0.99 & 8.00 & $35-26.5$ & 29.00 \\
CH_5 & 15.7 & 9.4 & 183 & 0.60 & 11.66 & $60-30$ & 56.00 \\
CH_6 & 16.0 & 8.5 & 220 & 0.53 & 13.75 & $76-20$ & 76.50 \\
CH_7 & 26.0 & 16.8 & 245 & 0.65 & 9.42 & $70-35$ & 80.00 \\
\hline
\end{tabular}

Table 1. Main characteristics of the seven chimneys. Note: $\mathrm{D}_{\text {base }}=$ diameter at the base; $\mathrm{D}_{\text {top }}=$ diameter at the top; $\mathrm{H}=$ height; $\mathrm{t}_{\mathrm{d}}=$ taper ratio; $\lambda=$ slenderness; $\mathrm{t}_{\mathrm{h}}=$ thickness of the circular hollow section; $\mathrm{q}_{\mathrm{k}}=$ distributed mass along the height.

The finite element model (FEM) of each chimney is implemented by MIDAS Gen software [16]. Each FEM has beam elements with a perfect restrain at the base. The self-weight and the dead loads are converted to mass in order to carry out the eigenvalue analyses for evaluating the periods, the related modal participation mass and the deformed shapes. The nonlinear material property of the concrete is attributed by Kent-Park property [17] and the ones attributed to the steel rebars is described in [18]. Eigenvalue results are shown in Table 2.

\begin{tabular}{|c|c|c|}
\hline Chimney & $\begin{array}{c}\mathrm{T}_{\mathrm{I}} \\
{[\mathrm{s}]}\end{array}$ & $\begin{array}{l}\mathrm{M}_{1} \\
{[\%]}\end{array}$ \\
\hline CH_1 & 1.63 & 58.48 \\
\hline $\mathrm{CH}_{-} 2$ & 0.90 & 66.51 \\
\hline $\mathrm{CH}_{-}^{-} 3$ & 1.77 & 54.24 \\
\hline $\mathrm{CH}_{-}^{-} 4$ & 1.33 & 63.82 \\
\hline $\mathrm{CH}_{-}^{-} 5$ & 2.55 & 53.87 \\
\hline CH_6 & 3.21 & 48.02 \\
\hline $\mathrm{CH}^{-} 7$ & 3.79 & 45.23 \\
\hline
\end{tabular}

Table 2. Eigenvalue analysis results. Note: $T_{1}$ is the first fundamental period and $M_{1}$ is the related involved mass 


\subsection{Seismic actions}

The seismic actions are represented by five acceleration times histories recorded during different European seismic events (Greece, Amatrice, L'Aquila, Friuli and Montenegro), included in the European Strong-Motion Database. The features of the seismic inputs are shown in Table 3. The seismic inputs have been selected in order to obtain Magnitude between 6 and 6.9 and a PGA value between $0.35 \mathrm{~g}$ and $0.53 \mathrm{~g}$ : however, they are characterized by different integral parameters values, gaining a large variability of the ground motion characteristics, $[19,20]$.

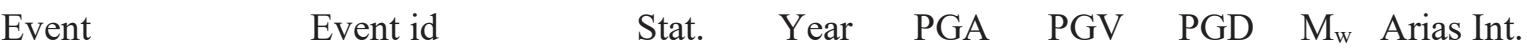

\begin{tabular}{ccccccccc}
{$[-]$} & {$[-]$} & {$[-]$} & {$[-]$} & {$[\mathrm{g}]$} & {$[\mathrm{cm} / \mathrm{s}]$} & {$[\mathrm{cm}]$} & {$[-]$} & {$[\mathrm{cm} / \mathrm{s}]$} \\
\hline $\begin{array}{c}\text { Friuli } \\
(\text { Acc1) }\end{array}$ & IT-1976-0030 & FRC & 1976 & 0.35 & 23.7 & 5.3 & 6 & 84.5 \\
$\begin{array}{c}\text { Montenegro } \\
(\text { Acc2) }\end{array}$ & ME-1979-0003 & PETO & 1979 & 0.45 & 38.5 & 6.9 & 6.9 & 455.7 \\
$\begin{array}{c}\text { Amatrice } \\
\text { (Acc3) }\end{array}$ & EMSC-20161030_0000029 & AMT & 2016 & 0.53 & 37.9 & 7.5 & 6.5 & 156.4 \\
$\begin{array}{c}\text { Greece } \\
\text { (Acc4) }\end{array}$ & GR-1995-0047 & AIGA & 1995 & 0.52 & 51.3 & 8.3 & 6.5 & 117.1 \\
$\begin{array}{c}\text { L'Aquila } \\
\text { (Acc5) }\end{array}$ & IT-2009-0009 & AQG & 2009 & 0.49 & 35.8 & 6.0 & 6.1 & 132.4 \\
\hline
\end{tabular}

Table 3. Characteristics of the seismic inputs.

\subsection{Tuned mass dampers parameters}

Once the vibration mode shapes and the main frequencies of the structures are known, the features of the TMDs can be evaluated according to [21,22] and the seismic response can be analyzed by introducing the TMDs in the FEMs of each chimney (system 2). The TMD is implemented through a nodal mass connected to the chimney with a spring and linear dashpot characterized by horizontal stiffness $\left(\mathrm{k}_{\mathrm{TMD}}\right)$ and damping coefficient $\left(\mathrm{C}_{\mathrm{TMD}}\right)$. The boundary conditions of the node representing the TMD are set to allow only the horizontal displacements of the mass. The horizontal stiffness $\left(\mathrm{k}_{\mathrm{TMD}}\right)$ and the related damping coefficient $\left(\mathrm{C}_{\mathrm{TMD}}\right)$ are evaluated considering the following relations [23]:

$$
\begin{gathered}
k_{T M D}=m \cdot \alpha_{o p t}^{2} \cdot \omega_{s}^{2} \\
C_{T M D}=2 \cdot \xi_{o p t} \cdot \sqrt{\left(k_{T M D} \cdot m_{d}\right)}
\end{gathered}
$$

From [24] the values of $\mathrm{k}_{\mathrm{TMD}}$ and $\mathrm{C}_{\mathrm{TMD}}$ are obtained starting from the definition of the ratio $(\mu)$ given by the ratio of the mass of TMD $\left(m_{d}\right)$ and the mass of the chimney $(m)$ involved in the main vibrational mode (already explained in Phase A) and $\omega_{\mathrm{s}}$ defined as the pulsation depending by the main frequency ( $f_{\mathrm{I}}$ corresponding to the frequency value of the first and second mode shapes of the chimney without TMD) by the equation (3): 


$$
\omega_{s}=2 \pi \cdot \mathrm{f}_{\mathrm{I}}
$$

The TMD mass ratio is given by the Eq.4 to obtain concerning the fundamental mode $\left(\mu_{1}\right)$ is given by:

$$
\mu_{1}=\frac{m_{d}}{\alpha_{1} \cdot m}
$$

where $\alpha 1$ is the participant mass ratio of the fundamental mode of the structure without the TMD. The general mass ratio $\mu$ is expressed as:

$$
\mu=\frac{m_{d}}{m}=\frac{\mu_{1} \cdot \alpha_{1} \cdot m}{m}=\mu_{1} \cdot \alpha_{1}
$$

In order to define $\mathrm{k}_{\mathrm{TMD}}$ and $\mathrm{C}_{\mathrm{TMD}}$, the optimal coefficient for the frequencies ( $\alpha$ opt) and the optimal equivalent viscous damping ratio $\left(\xi_{\mathrm{opt}}\right)$ are evaluated as it comes out from the following expressions, where $\xi$ is the equivalent damping ratio for the structure:

$$
\begin{gathered}
\alpha_{o p t}=\left(\frac{\sqrt{1-0.5 \mu}}{1+\mu}+\sqrt{1-2 \xi^{2}}-1\right)-(2.375-1.034 \sqrt{\mu}-0.426 \mu) \cdot \xi \cdot \mu-(3.730-16.903 \\
+20.496 \mu) \cdot \xi^{2} \cdot \sqrt{\mu} \\
\xi_{\text {opt }}=\sqrt{\left(\frac{\sqrt{3 \mu}}{8(1+\mu)(1-0.5 \mu)}\right)}+\left(0.151 \xi-0.175 \xi^{2}\right)+\left(0.163 \xi+4.98 \xi^{2}\right) \cdot \mu
\end{gathered}
$$

Basing on the previous relations the values of mass the TMD can be taken in the range $1 \% \div 5 \%$ of the mass of the chimney excited in correspondence of the main frequency (related to the first and second mode shapes). Testing different values of the TMD's mass, the related values of $\mathrm{k}_{\mathrm{TMD}}$ and $\mathrm{C}_{\mathrm{TMD}}$ (see relation (1) and (2)) can be detected and the different seismic response of "chimney with TMD" (system 2) can be evaluated in the FEMs where displacement, shear and moment variations are graphically shown in Figure 1. Once the average trends are detected for each chimney, the mass ratios optimizing the sizes of the TMDs are evaluated. The optimized size must minimize the mass of the damper but it must allow to reduce as far as possible the displacements, the base shear and base bending moment [4,25]. Therefore, for each chimney when the optimum mass ratio ( $\left.\mu_{\mathrm{OPT}}\right)$ is chosen, the features of each TMD are evaluated as well in terms of horizontal stiffness $\left(\mathrm{k}_{\mathrm{TMD}}\right)$ damping coefficient $\left(\mathrm{C}_{\mathrm{TMD}}\right)$ and pulsation $\left(\omega_{\mathrm{s}}\right)$ by the previous equations $(1 \div 3)$, see Table 4 . 


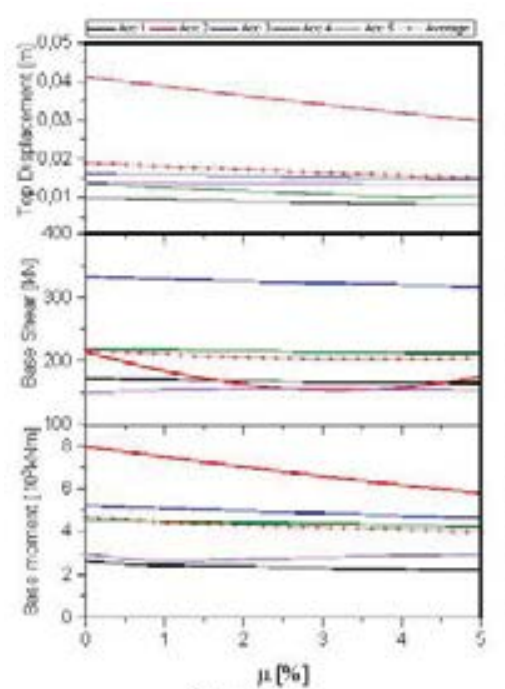

Chimney 1
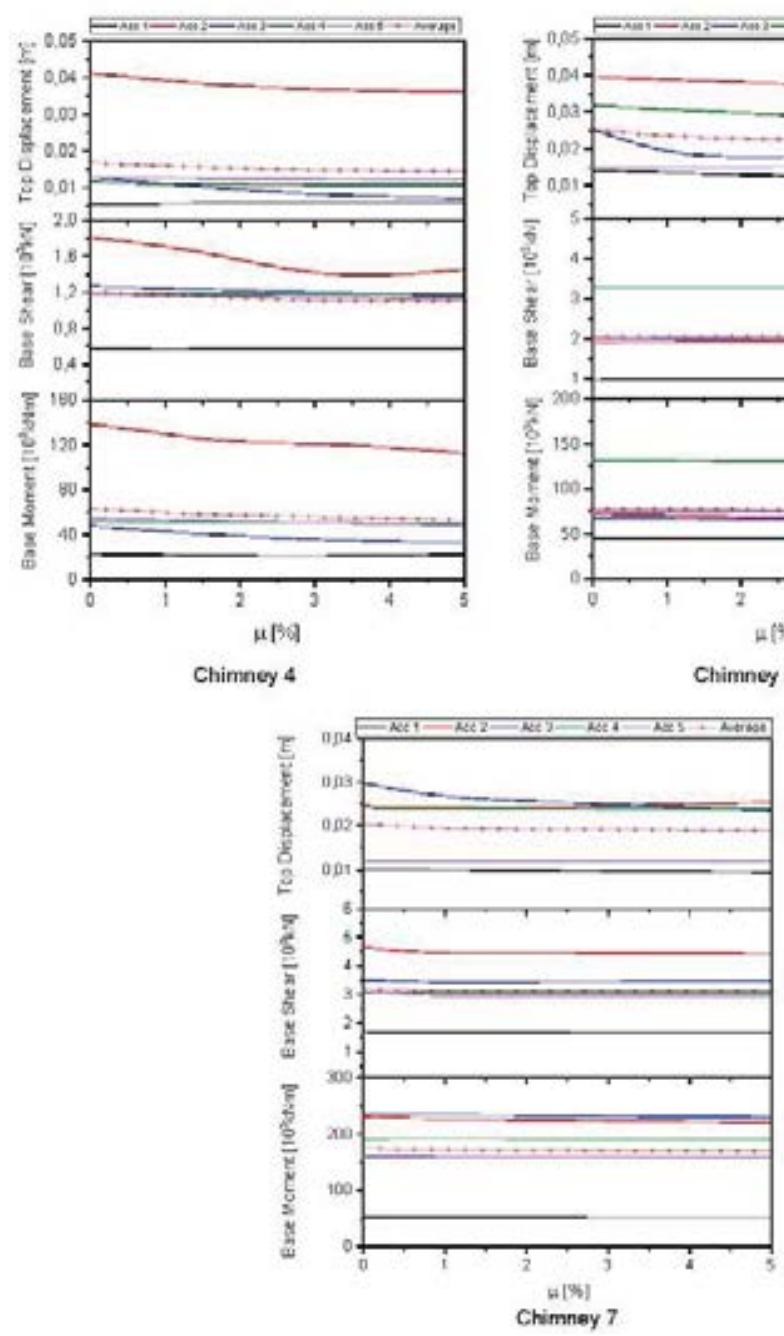

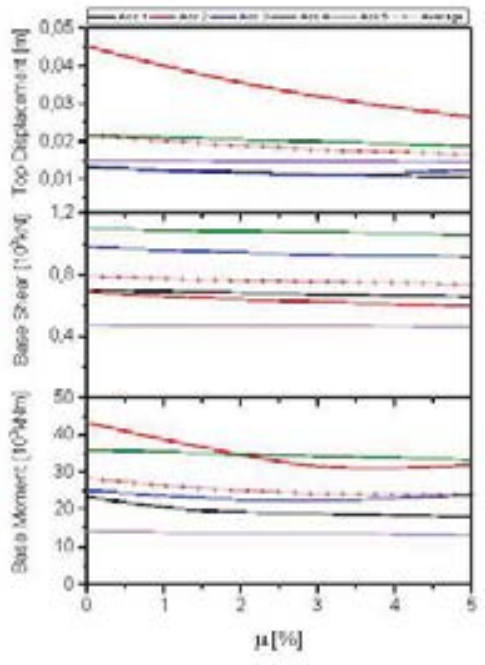

Chimney 3

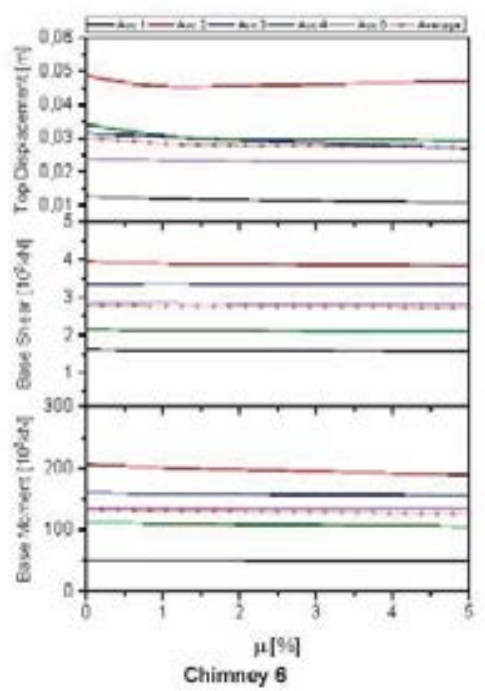

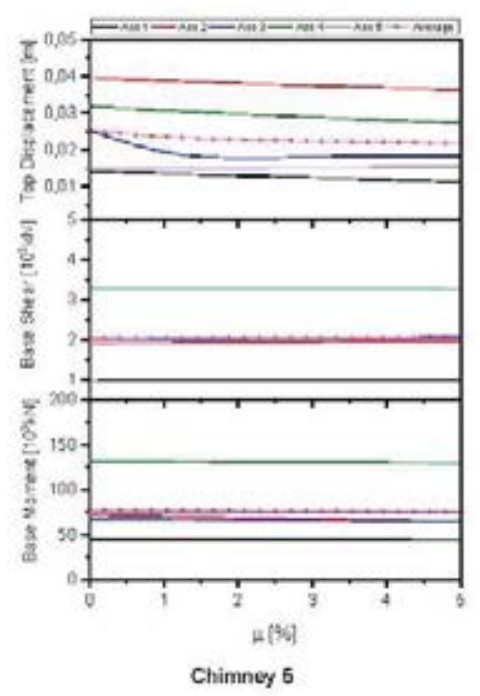

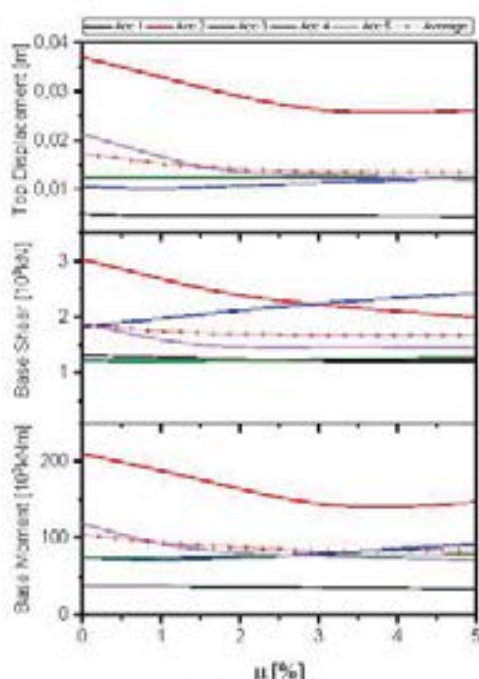

$\mu[\%]$

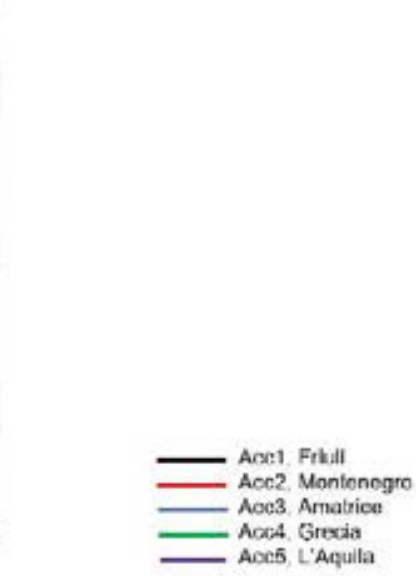

Figure 1. Optimization of the TMDs features in terms of top displacement, base shear and base moment in relation to the mass ratio for the seven existing chimneys 


\begin{tabular}{|c|c|c|c|c|c|c|c|}
\hline $\begin{array}{l}\text { Optimum TMD } \\
\text { Properties }\end{array}$ & CH_1 & CH_2 & CH_3 & CH_4 & CH_5 & CH_6 & CH_7 \\
\hline$\mu_{\mathrm{opt}}$ & $4 \%$ & $1.5 \%$ & $3 \%$ & $3 \%$ & $3 \%$ & $5 \%$ & $3 \%$ \\
\hline$\omega_{\mathrm{TMD}}$ & 0.58 & 1.08 & 0.54 & 0.72 & 0.38 & 0.29 & 0.26 \\
\hline $\mathrm{m}_{\text {tmd }}[\mathrm{kN} / \mathrm{g}]$ & 22.19 & 48.53 & 53.17 & 88.96 & 148.81 & 344.61 & 233.33 \\
\hline $\mathrm{k}_{\mathrm{TMD}}[\mathrm{kN} / \mathrm{m}]$ & 293.22 & 2224.90 & 613.50 & 1812.41 & 828.56 & 1148.62 & 589.11 \\
\hline $\mathrm{c}_{\mathrm{TMD}}[\mathrm{kNs} / \mathrm{m}]$ & 20.47 & 52.56 & 40.00 & 88.92 & 77.77 & 177.43 & 82.11 \\
\hline
\end{tabular}

Table 4. Properties of the optimum tuned mass dampers selected for the seven chimneys $\left(\mathrm{CH}_{-}\right.$identifies the chimneys).

\section{EQUIVALENT DAMPING EVALUATION}

The contribution of the mass dampers of each chimney in terms of equivalent damping $\left(\xi_{\mathrm{e}}\right)$ is here estimated starting from the dynamic amplification factor $(\mathrm{H})$ given by the ratio between $X_{s}$ and $X_{d}$, where $X_{s}$ is the top displacement under seismic action and $X_{d}$ is the dynamic top displacement under forces with frequencies included in the range $(0.8 \div 1.2) \cdot f_{I}$ where $f_{I}$ corresponds to the frequency to smooth (this value is obviously different for each chimney). The ratio between the frequencies of the forces and the frequency to smooth is called $\rho$ (the variation of $\mathrm{H}$ by $\rho$ is shown in Figure 2). The equivalent damping $\left(\xi_{\mathrm{e}}\right)$ due to the TMDs can be detected as well from $\mathrm{H}$ because $\xi_{\mathrm{e}}$ is given by the relation (7) and it can be plotted once again in relation to $\rho$. The final value of the equivalent damping corresponds to the average one of the two lower peaks of the diagrams $\xi_{\mathrm{e}}-\rho$ (Figure 3):

$$
\xi_{e}=\frac{H}{2}
$$

It is worth nothing the influence of the main frequency of the chimney in the TMD's contribution in terms of equivalent damping given to the main structure. The results plotted in the Figure 2 and Figure 3, respectively in terms of dynamic amplification factor $(\mathrm{H})$ and equivalent damping $\left(\xi_{\mathrm{e}}\right)$, are useful in order to appreciate the smooth effects given by the TMDs for each chimney under the five seismic events. The equivalent damping values are summarized in Table 5; the variation of the equivalent damping in relation to the frequencies of the chimneys is shown in Figure 4. 


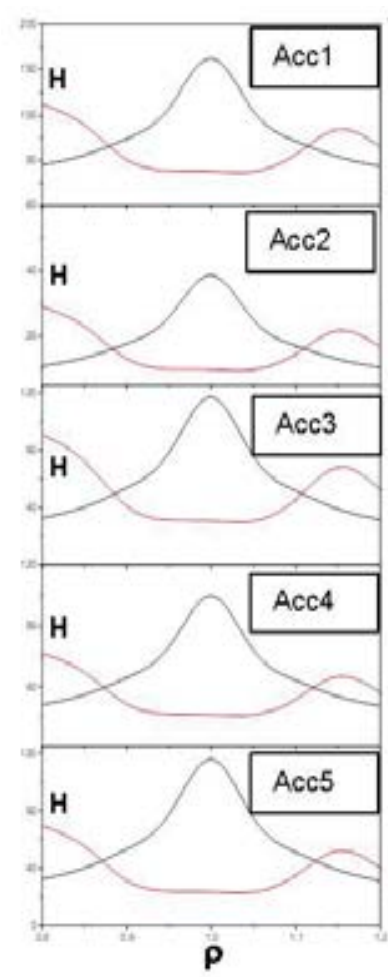

CHIMNEY 1

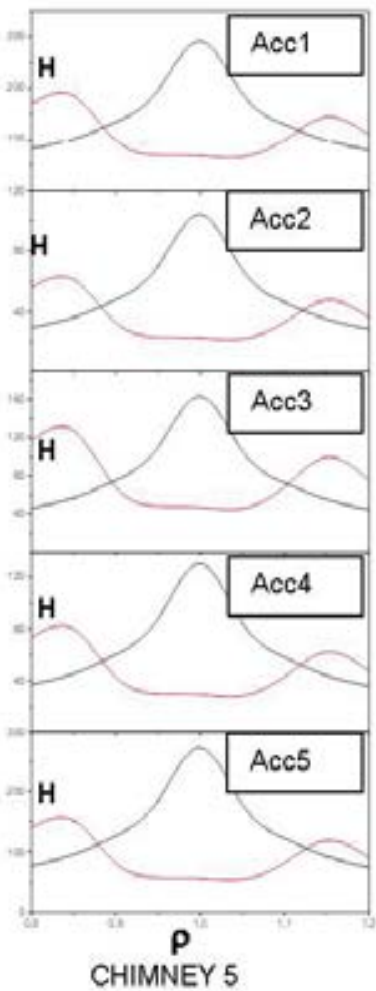

CHIMNEY 5

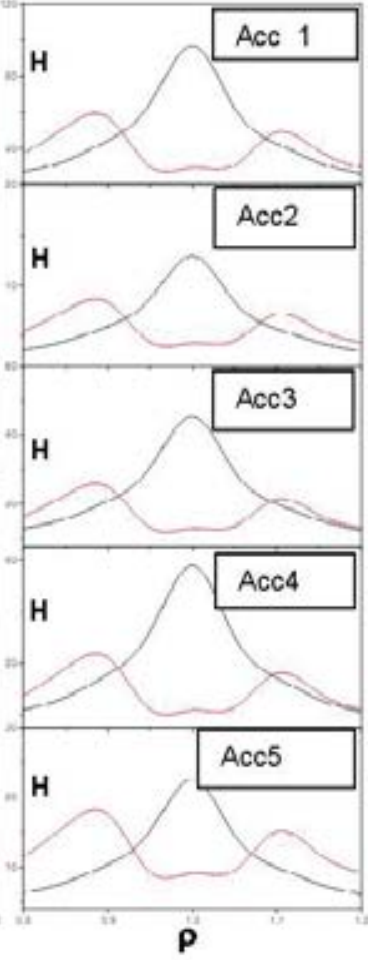

CHIMNEY 2

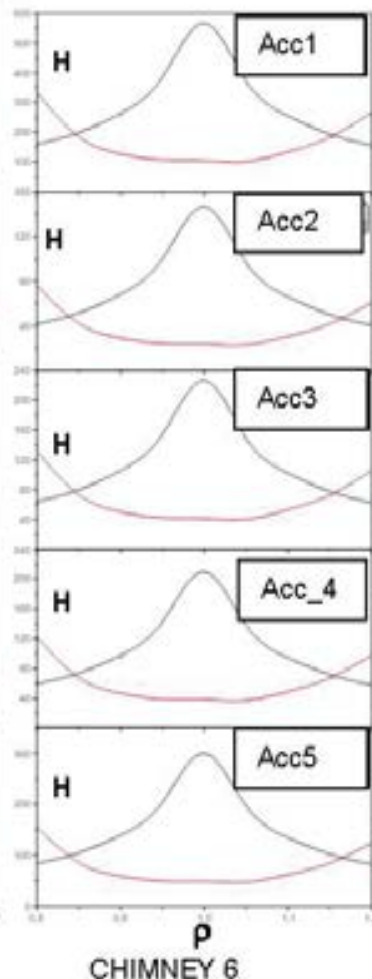

CHIMNEY 6

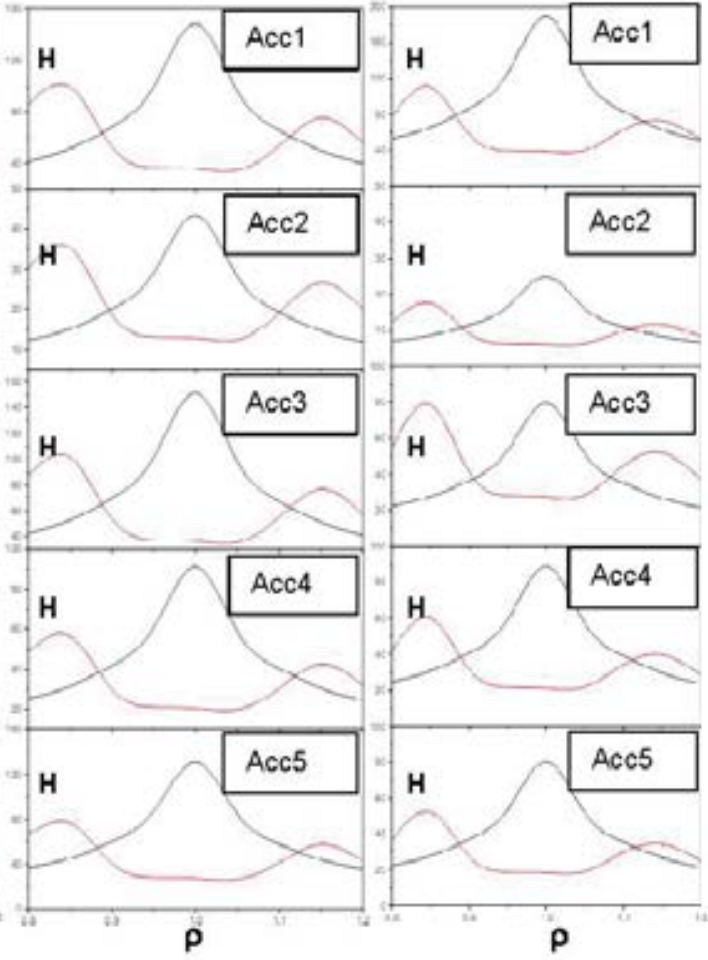

CHIMNEY 4

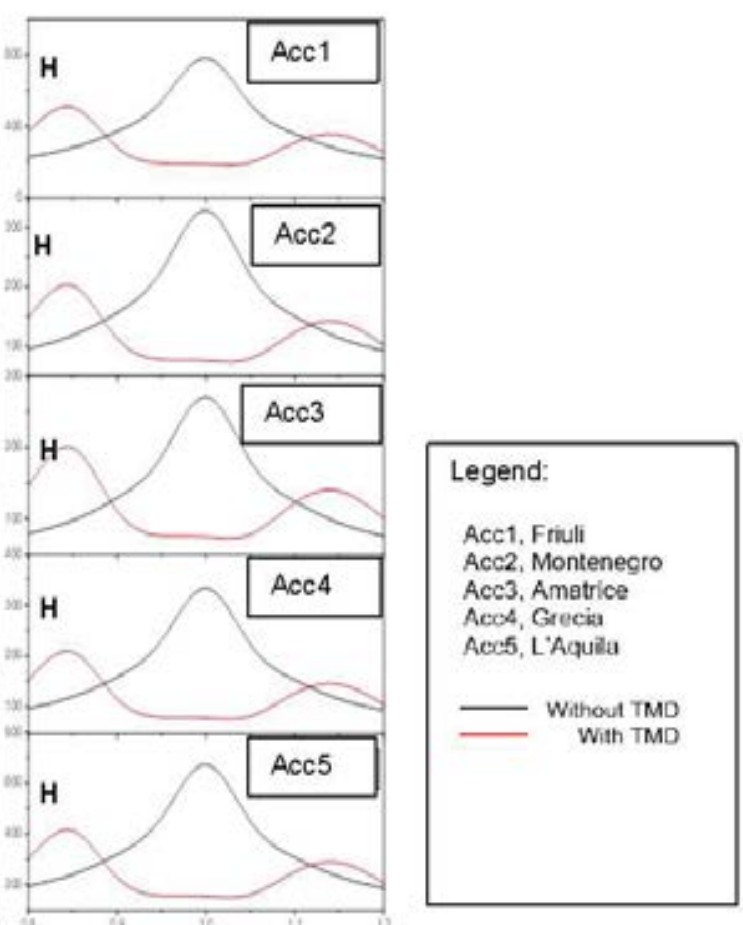

CHIMNEY 7

Figure 2. Dynamic Amplification Factor $(H)$ in relation to the frequency ratio $(\rho)$ 

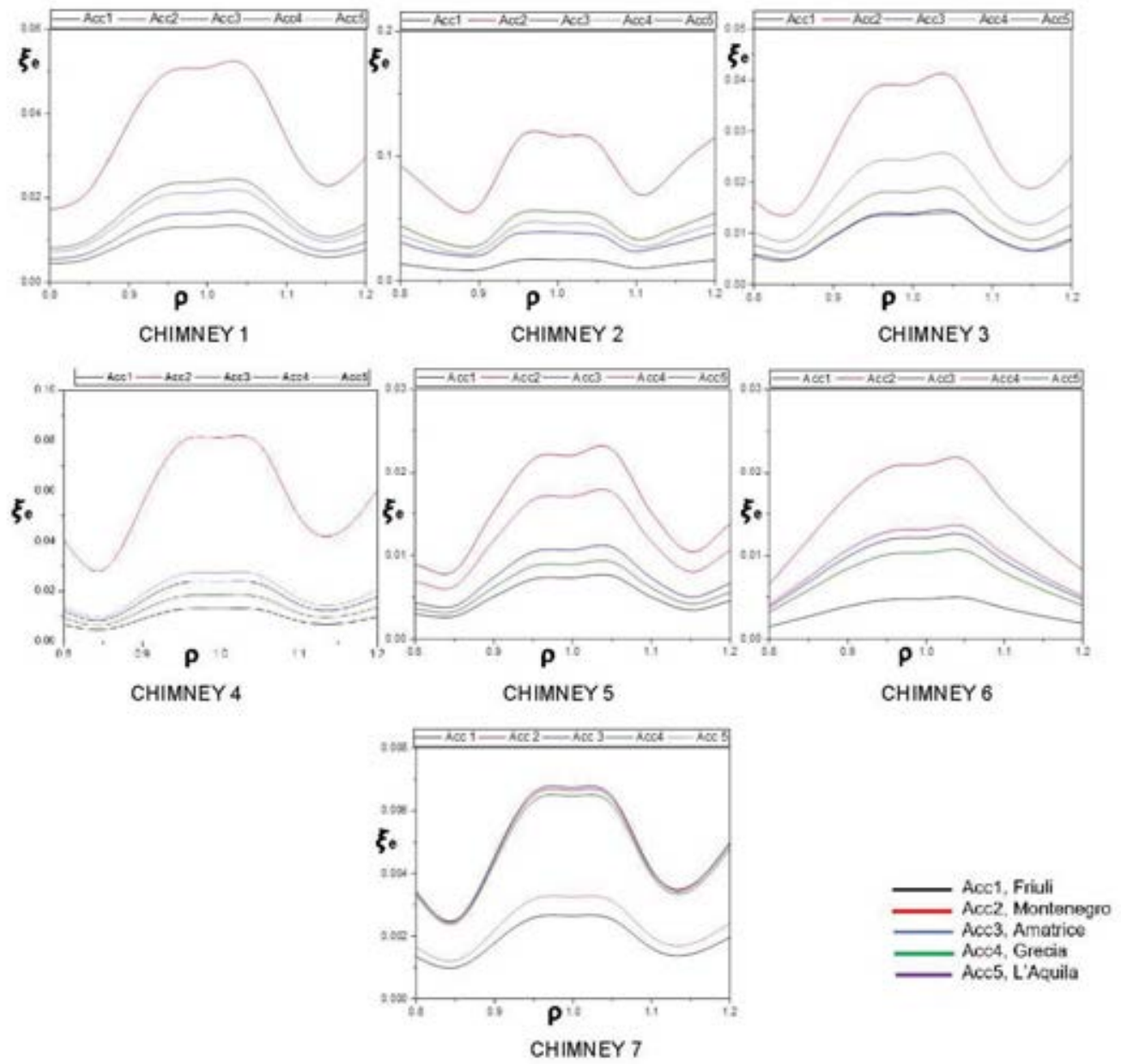

Figure 3. Equivalent Damping $\left(\xi_{\mathrm{e}}\right)$ in relation to the frequency ratio $(\rho)$ for the five earthquakes

\begin{tabular}{lllllllll} 
& \multicolumn{2}{c}{ Chimney } & Chimney & Chimney & Chimney & \multicolumn{2}{c}{ Chimney } & \multicolumn{2}{c}{ Chimney } & Chimney \\
& \multicolumn{1}{c}{1} & 2 & 3 & 4 & 5 & 6 & 7 \\
Acc & $\xi_{\mathrm{e}}$ & $\xi_{\mathrm{e}}$ & $\xi_{\mathrm{e}}$ & $\xi_{\mathrm{e}}$ & $\xi_{\mathrm{e}}$ & $\xi_{\mathrm{e}}$ & $\xi_{\mathrm{e}}$ \\
1 & 0.0076 & 0.011 & 0.008 & 0.007 & 0.004 & 0.003 & 0.001 \\
2 & 0.0309 & 0.077 & 0.026 & 0.047 & 0.012 & 0.010 & 0.004 \\
3 & 0.0101 & 0.023 & 0.008 & 0.013 & 0.007 & 0.007 & 0.004 \\
4 & 0.0128 & 0.027 & 0.013 & 0.013 & 0.009 & 0.007 & 0.004 \\
5 & 0.0112 & 0.041 & 0.009 & 0.015 & 0.005 & 0.005 & 0.002 \\
\hline
\end{tabular}

Table 5. Equivalent damping $\xi$ e for the seven chimneys in correspondence of the five seismic events 


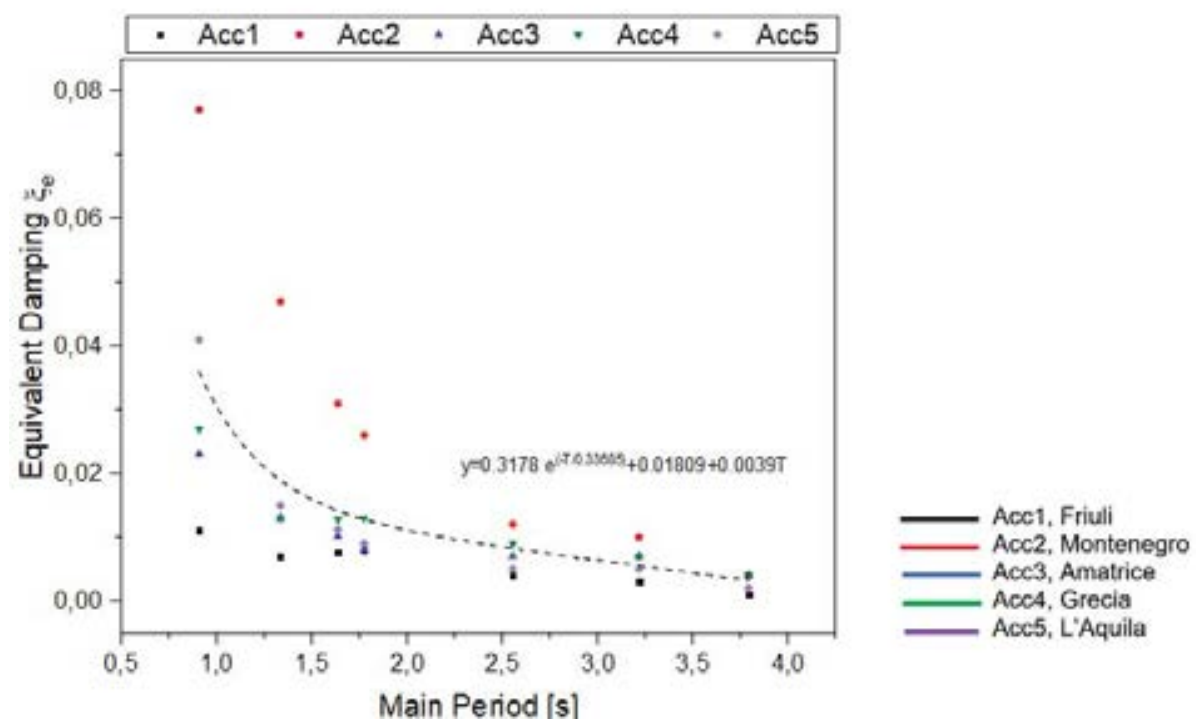

Figure 4. Variation of the equivalent damping with respect to the main periods of the seven chimneys.

\section{ENERGETIC CONTRIBUTION OF THE TUNED MASS DAMPERS}

In the present phase the dynamic behavior of the five case studies (chimneys with TMDs) is deepen in terms of energy damping starting from the assumption that for the generic chimney the input energy $\left(\mathrm{E}_{\mathrm{i}}\right)$ due to the seismic action is the work done by the ground motion on the construction. Considering the time dependent conservation of the energy, $\left(E_{i}\right)$ is given by the summation of the kinetic energy $\left(E_{k}\right)$, the elastic strain energy $\left(E_{s}\right)$, the energy dissipated by the structure throughout the inelastic features $\left(\mathrm{E}_{h}\right)$ and the damped dissipative energy of the building and the mass damper if present $\left(E_{d}\right)$. Formulations about the energies are present in $[26,27]$. The aim of this phase is the evaluation of the damping energy during each seismic event for the seven chimneys either in the case chimneys without TMD and chimneys with TMDs. In Figure 5, for each chimney, the damping energy $\left(E_{d}\right)$ is plotted for the five accelerograms. The output of the energetic analyses represents the variation of the damping energy during the seismic events therefore the results of this kind of analysis is plotted by time histories in both cases (chimneys without and with TMDs). Each time history represents the percentage of the damping energy with respect to the input energy. 

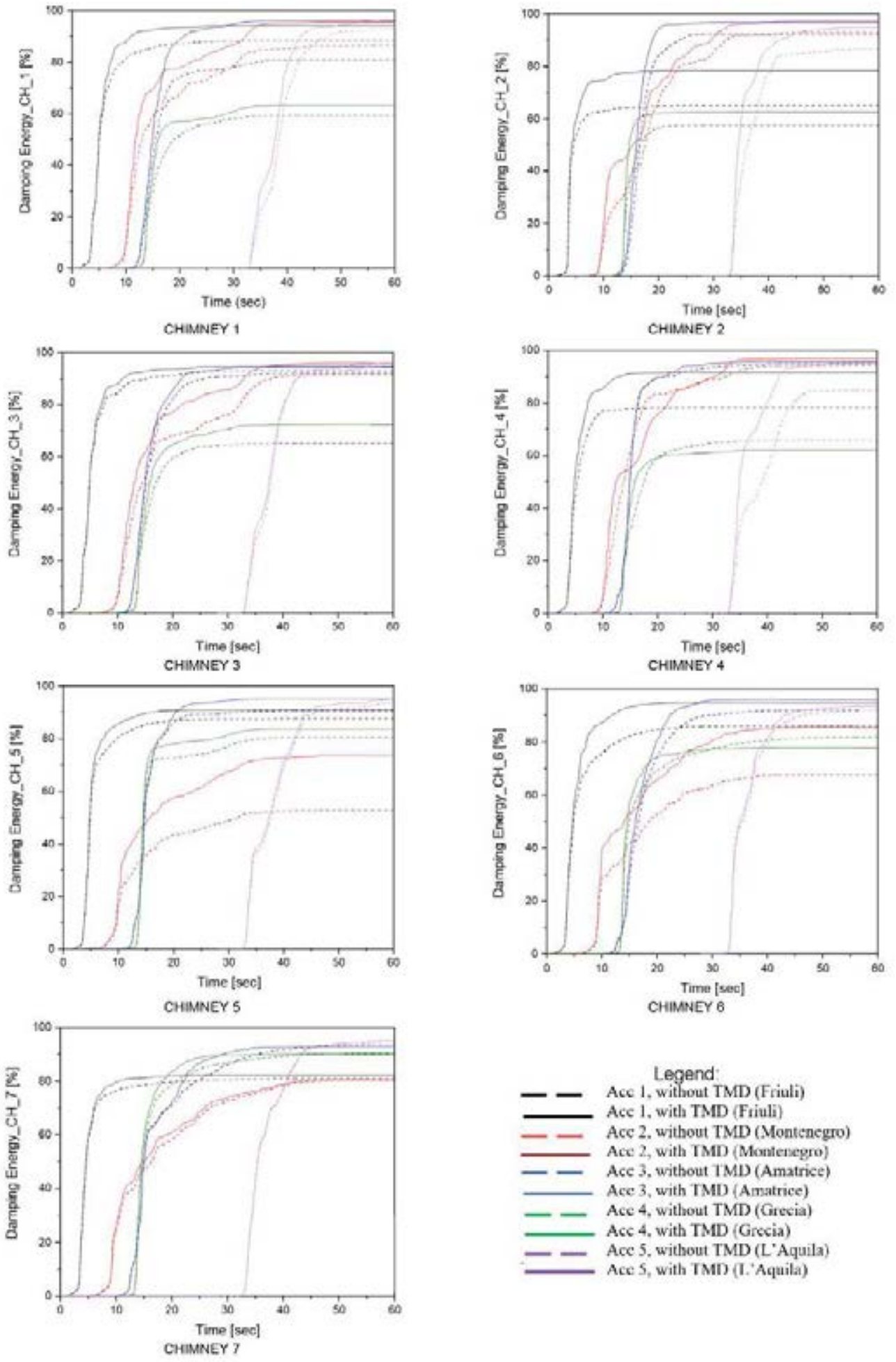

\section{Legend}

- - Acc 1, without TMD (Friuli)

Ace 1, with TMD (Friuli)

Ace 2, without TMD (Montenegro)

Ace 2, with TMD (Monteregro)

Ace 3, without TMD (Amatrice)

Ace 3, with TMD (Amatrice)

Ace 4, without TMD (Gresia)

Acc 4, with TMD (Grecia)

Acc 5, without TMD (L'Aquila)

Ace S, with TMD (I.'Aquila)

Figure 5. Evaluation of the percentage of the damping energy (Ed)with respect the input energy (Ei) 


\section{REMARKS}

- The use of the Tuned Mass Dampers for existent Reinforced Concrete chimneys represents a valid solution for improving the seismic response of this kind of construction especially if originally built in areas only nowadays classified as seismic areas;

- The size of the TMD is influenced by the geometrical features of the chimneys: in fact, chimneys with high slenderness values need TMD with optimum mass ratio $\mu$ opt higher than the ones with low slenderness. For slenderness value around $\lambda=10$ the optimum mass ratio $\mu$ opt is around 3\% but for higher slenderness values, as it is for $\mathrm{CH} 6$ with $\lambda \mathrm{CH} \_6=13.75$, higher mass ratio $\mu \mathrm{opt}-\mathrm{CH} \_6=5 \%$ is adopted; vice versa $\mathrm{CH}_{-} 2$ with slenderness $\lambda \mathrm{CH}_{-} 2=6.21$ needs lower mass ratio $\mu$ opt $-\mathrm{CH} 22=1.5 \%$; similar consideration may not be valid about the effect of the taper ratio td on the size of the TMD because chimneys with different $\mathrm{td}$, as $\mathrm{CH}_{-} 1$ with $\mathrm{td}=0.52$ and $\mathrm{CH}_{-} 4$ with $\mathrm{td}=0.99$, are characterized by mass ratio values very close themselves (e.g. $\mu$ opt- $\mathrm{CH}_{-} 1=4 \%$ and $\mu$ opt-CH_4 = 3\%);

- In the seismic events here adopted, the most important variations with the TMDs occur in terms of top displacement for each chimney; although, the base shear variation is not appreciable for each chimney especially in comparison to the displacements and moment variations;

- the equivalent damping does not appear dependent by the individual features of the chimneys (even if for high value of the geometrical slenderness - as it is for chimneys 1 , 5 and 6 respectively with $\lambda_{\mathrm{CH}_{-} 1}=12.5, \lambda_{\mathrm{CH}_{-} 5}=11.66$ and $\lambda_{\mathrm{CH}_{-} 6}=13.75-$ the equivalent damping values are very similar themselves); it is worth nothing the equivalent damping due to the TMD depends on the characteristics of the seismic event combined to the natural frequency of each single chimney, thus the seismic response is a correlation between the chimney's features (as the height, taper ratio, slenderness and dead loads) and the ones of each seismic event shacking the construction. A relation between the equivalent damping and the main periods of the chimneys (T) is expressed in the relation shown in Figure 4 where the equivalent damping $\xi_{\mathrm{e}}$ here estimated exhibits exponential variation growing for the lower values of T; vice versa, the intensity of the strong motion becomes irrelevant when the main period increases.

$$
\xi_{e}=0.3178 \cdot e^{-\frac{T}{0.3368 \overline{5}}}+0.01809+0.0039 T
$$

- under the five earthquakes the damping energy for the seven chimneys increases thanks to the TMDs; the contribution of TMDs is much evident in the asymptotic branch of the curves, especially under accelerograms 1 and 2 (drawn by black and red lines. In the case chimneys with TMDs, the damping energy increases. Generally, the dissipation of the input energy due to the seismic event occurs for damping contribute whereas the one due to the strain energy is practically zero. At the same time the TMD slightly reduces the contribute of kinetic energy in the dissipation of the input energy.

\section{REFERENCES}

[1] DIVER M. CALCUL PRATIQUE DES CHEMINEES EN BETON ARME. Inst Tech Batim Des Trav Publics-Annales 1969. 
[2] NTC2018. Norme Tecniche per le Costruzioni. 2018.

[3] Elias S, Matsagar V, Datta TK. Distributed Multiple Tuned Mass Dampers for Wind Response Control of Chimney with Flexible Foundation. Procedia Eng., 2017. https://doi.org/10.1016/j.proeng.2017.09.087.

[4] Elias S, Matsagar V. Research developments in vibration control of structures using passive tuned mass dampers. Annu Rev Control 2017. https://doi.org/10.1016/j.arcontrol.2017.09.015.

[5] Elias S, Rupakhety R, Ólafsson S. Tuned Mass Dampers for Response Reduction of a Reinforced Concrete Chimney Under Near-Fault Pulse-Like Ground Motions. Front Built Environ 2020. https://doi.org/10.3389/fbuil.2020.00092.

[6] Elias S, Matsagar V, Datta TK. Effectiveness of distributed tuned mass dampers for multi-mode control of chimney under earthquakes. Eng Struct 2016. https://doi.org/10.1016/j.engstruct.2016.06.006.

[7] Longarini N, Cabras L, Zucca M, Chapain S, Aly AM. Structural Improvements for Tall Buildings under Wind Loads: Comparative Study. Shock Vib 2017;2017. https://doi.org/10.1155/2017/2031248.

[8] Longarini N, Zucca M, Silvestro G. The constructions vibration control by tuned mass dumper. IABSE Conf. Geneva 2015 Struct. Eng. Provid. Solut. to Glob. Challenges Rep., 2015.

[9] Wilson JL. Earthquake response of tall reinforced concrete chimneys. Eng Struct 2003. https://doi.org/10.1016/S0141-0296(02)00098-6.

[10] Wilson JL. The cyclic behaviour of reinforced concrete chimney sections with and without openings. Adv Struct Eng 2009. https://doi.org/10.1260/136943309788708329.

[11] Wang L, Fan X yan. Failure cases of high chimneys: A review. Eng Fail Anal 2019. https://doi.org/10.1016/j.engfailanal.2019.07.032.

[12] Bońkowski PA, Zembaty Z, Minch MY. Seismic effects on leaning slender structures and tall buildings. Eng Struct 2019. https://doi.org/10.1016/j.engstruct.2019.109518.

[13] Tabeshpour MR. Nonlinear dynamic analysis of chimney-like towers. Asian J Civ Eng 2012.

[14] Bońkowski P, Zembaty Z, Minch MY. Nonlinear interaction of initial leaning of r/c slender tower with its seismic response. Insights Innov. Struct. Eng. Mech. Comput. Proc. 6th Int. Conf. Struct. Eng. Mech. Comput. SEMC 2016, 2016. https://doi.org/10.1201/9781315641645-50.

[15] Akyürek O, Suksawang N, Go TH, Tekeli H. Performance evaluation of a reinforced concrete building strengthened respectively by the infill wall, active and passive tuned mass damper under seismic load. Comput Struct 2019. https://doi.org/10.1016/j.compstruc.2019.07.006.

[16] Midas. Midas GEN FX Program - General structure design system n.d.

[17] Park R, Kent DC, Sampson RA. REINFORCED CONCRETE MEMBERS WITH CYCLIC LOADING. ASCE J Struct Div 1972.

[18] Scott BD, Park R, Priestley MJN. STRESS-STRAIN BEHAVIOR OF CONCRETE CONFINED BY OVERLAPPING HOOPS AT LOW AND HIGH STRAIN RATES. J 
Am Concr Inst 1982. https://doi.org/10.14359/10875.

[19] Zucca M, Tropeano G, Erbì E, Crespi P. Evaluation of the seismic behavior of multipropped shallow underground structures embedded in granular soils: A comparison between coupled and decoupled approaches. Earthq. Geotech. Eng. Prot. Dev. Environ. Constr. Proc. 7th Int. Conf. Earthq. Geotech. Eng. 2019, 2019.

[20] Zucca M, Valente M. On the limitations of decoupled approach for the seismic behaviour evaluation of shallow multi-propped underground structures embedded in granular soils. Eng Struct 2020. https://doi.org/10.1016/j.engstruct.2020.110497.

[21] Tsai H -C, Lin G -C. Optimum tuned-mass dampers for minimizing steady-state response of support-excited and damped systems. Earthq Eng Struct Dyn 1993. https://doi.org/10.1002/eqe.4290221104.

[22] Ormondroyd J, Den Hartog JP. The theory of the dynamic vibration absorber. Trans Am Soc Mech Eng 1928.

[23] Li C, Qu W. Optimum properties of multiple tuned mass dampers for reduction of translational and torsional response of structures subject to ground acceleration. Eng Struct 2006. https://doi.org/10.1016/j.engstruct.2005.09.003.

[24] Hoang N, Fujino Y, Warnitchai P. Optimal tuned mass damper for seismic applications and practical design formulas. Eng Struct 2008. https://doi.org/10.1016/j.engstruct.2007.05.007.

[25] Longarini N, Zucca M. A chimney's seismic assessment by a tuned mass damper. Eng Struct 2014;79. https://doi.org/10.1016/j.engstruct.2014.05.020.

[26] Elias S. Seismic energy assessment of buildings with tuned vibration absorbers. Shock Vib 2018. https://doi.org/10.1155/2018/2051687.

[27] Anam I, Manju F, Khan F. Seismic vibration control of nonlinear RC structures. Wind Earthq. Eng. - Proc. 10th East Asia-Pacific Conf. Struct. Eng. Constr. EASEC 2010, 2006. 